\title{
PALAVRAS PARA LER, ENTENDER E SENTIR PAULO FREIRE
}

\author{
Júlio César Virgínio da Costa*
}

STRECK, D. R.; REDIN, E.; ZITKOSKI, J. J. (Orgs.). Dicionário Paulo Freire. 2. ed. rev. e ampl. Belo Horizonte: Autêntica Editora, 2010. 439 p.

A Palavra Mágica

Certa palavra dorme na sombra de um livro raro. Como desencantá-la? É a senha da vida a senba do mundo. Vou procurá-la.

Vou procurá-la a vida inteira no mundo todo.

Se tarda o encontro, se não a encontro, não desanimo, procuro sempre.

Procuro sempre, e minha procura ficará sendo minha palavra.

Uma recensão sobre um dicionário não é uma obra muito comum de se ver, mas nesse caso se justifica pela própria ontologia do pensamento e da existência ao qual a obra faz alusão: Paulo Freire, um dos maiores pensadores e educadores da e na educação brasileira e também internacional. Educação, esta, pautada por uma concepção humanista e baseada na práxis humana em sua maior plenitude possível. Segundo Paulo Renato de Souza (2004, p. 5 apud BARRETO, 2004), na apresentação da obra Paulo Freire

\footnotetext{
*Doutorando em Educação pela Universidade Federal de Minas Gerais (UFMG); Membro do Labepeh (Laboratório de Estudos e Pesquisas em Ensino de História) e Bolsista Reuni da Faculdade de Educação da UFMG e Professor de História da Educação Básica na Rede Privada em Belo Horizonte. E-mail: juliocesarhistoria@gmail.com
} 
para educadores, a pedagogia de Paulo Freire inspirou os principais programas de alfabetização e educação popular no início dos anos 60 e seu legado teórico e prático é uma referência internacional na área da educação. Dessa maneira, o Dicionário Paulo Freire é um trabalho que busca colaborar para a leitura das diversas obras desse grande educador, da compreensão do pensamento/conceitos/pressupostos filosóficos do ato reflexivo/crítico e da ação pedagógica que influenciou e influencia muitas práticas educativas em diversos ambientes educativos na busca por uma maior compreensão da força de suas palavras.

Obra organizada por Danilo R. Streck, professor no Programa de Pós-Graduação em Educação da Universidade do Vale do Rio dos Sinos (Unisinos), com doutorado em Educação (Rutgers University, USA); por Euclides Redin, doutor em Psicologia Escolar e Desenvolvimento Humano (USP), professor da Universidade Federal de Viçosa (MG) de 1980 a 1992 e do Programa de Pós-Graduação em Educação da Unisinos de 1993 a 2007; e por Jaime José Zitkoski, doutor em Educação (UFRGS), atualmente professor de Filosofia da Educação na Faced/UFRGS e do Programa de Pós-Graduação em Educação da mesma instituição.

No momento em que a educação é cada vez mais convocada a assumir seu papel para uma formação mais crítica e reflexiva no mundo e para o mundo, entender a força da palavra, os sentidos e as ações das expressões de Paulo Freire ganha mais vigor. Dessa forma, os autores, na apresentação da obra, nos informam que:

Paulo Freire foi um semeador e cultivador de palavras. Não de quaisquer palavras, mas de palavras "grávidas de mundo", como dizia. Palavras que têm o dom de gerar mundos, de pronunciar novas realidades. A intencionalidade que orientou a organização deste Dicionário Paulo Freire foi a de apreender sua trajetória humanizadora. Ninguém terá pretendido dizer a palavra derradeira sobre nada. No sentido de Freire, como reafirmado várias vezes ao longo deste Dicionário, buscou-se, isso sim, fazer um exercício do pensar certo na perspectiva de uma reflexão rigorosa e metódica. (STRECK; REDIN; ZITKOSKI, 2010, p. 13).

Para Paulo Freire, a palavra é potência transformadora, é mais que mero blá-blá-blá, assim, um Dicionário Paulo Freire ganha sentido de sua própria existência. Como Drummond, a palavra é senha da vida, a palavra mais ação é igual à práxis. Mas, iniciada pela palavra. 
Para Freire (2005, p. 12), em Pedagogia do oprimido, com a palavra o homem se faz homem. Dessa maneira, entender o significado, o contexto e a força de cada expressão na obra freireana é de extrema importância para uma melhor compreensão do pensamento e da vida desse educador que valoriza tanto a palavra.

Vou procurá-la a vida inteira no mundo todo.

Se tarda o encontro, se não a encontro, não desanimo, procuro sempre. (ANDRADE, 1994, p. 109).

Nessa segunda edição (agora revisada e ampliada), Danilo Streck, Euclides Redin e Jaime José Zitkoski (Orgs.) empreendem um trabalho de acesso ao universo vocabular de Paulo Freire com grande acuidade e primor na elaboração da obra e de cada verbete. Obra que se destina a educadores, estudantes de graduação e de pós-graduação e pesquisadores que também vivem e sonham (e refletem em sua práxis cotidiana), como Paulo Freire, por uma educação como prática da liberdade. Do dicionário organizado por esses três autores participam 104 estudiosos/conhecedores da obra e vida de Freire - incluindo os organizadores -, gerando 416 verbetes em ordem alfabética. Segundo eles, "[...] a seleção dos verbetes teve como referência o lugar que a palavra, expressão ou conceito ocupa na obra de Paulo Freire e a recorrência de seu uso.” (STRECK; REDIN; ZITKOSKI, 2010, p. 14). Procurando sempre o sentido... "e vou procurá-la a vida inteira...", assim nos diz o poeta!

Pode-se perceber um trabalho de fôlego e primoroso no acabamento final de cada verbete que, além do próprio conceito, abarca uma lista das obras utilizadas como referência bibliográfica para construção de cada expressão apresentada, proporcionando, assim, mais informações, indicações de leituras e, dessa maneira, a ampliação da compreensão da complexa elaboração do dicionário e do pensamento do próprio Paulo Freire. Alguns participantes tiveram a oportunidade de contribuir com mais de um verbete. Também é possível identificar participantes de outros países, demonstrando, dessa forma, a amplitude e o alcance - já conhecidos - da leitura das obras do autor. A saber: Peter McLaren, Jean-Christofe Noel, Jenifer Crawford, Jevdet Rexhepi e Henry Giroux, dentre outros. É claro que pesquisadores/ 
intelectuais brasileiros e latino-americanos estão fortemente ligados à elaboração dessa obra também, pensadores que estiveram próximos de Paulo Freire fisicamente e/ou intelectualmente. Por exemplo, Carlos Rodrigues Brandão, com os verbetes Andarilhagem, Círculo de cultura, Cultura, Cultura popular e Método Paulo Freire; Moacir Gadotti, com os verbetes Escola, Poder e Realidade; Leonardo Boff, com o verbete Transcendência; Maria Isabel da Cunha, com Discência/Docência e Professor (ser) ; e Osmar Fávero, com o verbete Coerência, dentre outros pensadores e pesquisadores.

Alguns conceitos de Paulo Freire são chaves de leitura fundantes em sua epistemologia, como, por exemplo, Ação-reflexão. Esse verbete é apresentado por Luiz Gilberto Kronbauer que, com muito cuidado na escrita, faz uma construção histórica do termo, identificando suas raízes epistemológicas e sempre buscando sua contextualização nas obras de Freire. Ao longo do verbete, Kronbauer faz citações das obras nas quais se debruçou para a elaboração desse conceito e demonstra que esse elemento da obra freireana designa o binômio da unidade dialética da práxis - supondo que essa seja o fazer e o saber reflexivo da ação, o saber que, segundo o autor, realimenta criticamente o fazer (STRECK; REDIN; ZITKOSKI, 2010, p. 23). Dessa forma, é possível perceber a construção do percurso metodológico e epistemológico do conceito ali analisado e esclarecido ao leitor.

Já Hernando Vaca Gutiérres esclarece os conceitos de Codificação/ Decodificação, esses que estão ligados diretamente à questão da dialogicidade na prática educativa em Paulo Freire, outro conceito chave de grande importância no pensamento freireano. Para Gutiérres, “[...] a decodificação é um ato cognoscente que promove o surgimento de nova percepção e o desenvolvimento de novo conhecimento." (STRECK; REDIN; ZITKOSKI, 2010, p. 72). Essa proposição está inserida no processo di alógico da superação das "situações-limite" no pensamento e ação do método Paulo Freire, portanto, conceito fundamente na compreensão de uma prática educacional humanista e libertadora.

Jerônimo Sartori teve a incumbência de elaborar o verbete/ conceito da Educação bancária/Educação problematizadora, conceito também importante na leitura das obras de Freire. Da mesma forma, com grande elaboração e acuidade, Sartori vai tecendo uma trama construtiva desse conceito e de sua historicidade. Para ele, a prática da educação bancária - na concepção freireana - é ato de subordinação do educando, ato que reprime 
sua curiosidade, desestimula a capacidade de desafiar-se, de arriscar-se e o torna, assim, um ser passivo, que o conceito/prática de uma educação problematizadora combate. Dessa maneira, apresenta-se uma proposta desafiadora que procura a emersão das consciências para que aconteça a inserção crítica do sujeito na realidade (STRECK; REDIN; ZITKOSKI, 2010). Para Sartori, a educação problematizadora em Freire se realiza nas relações entre o sujeito e o mundo, constituindo-se em relações de transformação e inaugurando a "conscientização", o que a educação bancária busca anular.

Diante da difícil escolha de quais verbetes indicar, não poderíamos deixar de comentar um dos que são, reconhecidamente, conceitos chave na vida e na obra freireana, o conceito de Leitura do mundo. Esse verbete/ conceito ficou a cargo de Luiz Augusto Passos, que com uma escrita potente e direta fornece elementos para compreender o valor dessa expressão nos pressupostos filosóficos e pedagógicos de Paulo Freire. Para o autor do verbete, “[...] a leitura do mundo e da palavra é, em Freire, direito subjetivo, pois, dominando signos e sentidos, nos humanizamos, acessando mediações de poder e cidadania." (STRECK; REDIN; ZITKOSKI, 2010, p. 238).

Dessa maneira, uma educação pelos sentidos se apresenta de maneira imbricada nos pressupostos educativos freireanos, demonstrando, assim, a atualidade do pensamento de Paulo Freire. Ler o mundo é um descortinar-se também na existência do próprio mundo, muitas vezes negada aos oprimidos e excluídos desse mesmo mundo. A descrição/análise desse conceito freireano é bem mais ampla do que se costuma - no senso comum - acreditar. Ele não é uma proposta apenas de incentivar o/no educando a uma leitura do mundo na perspectiva de quem ensina, pois, para Freire, não se aprende sozinho, mas em comunhão. A leitura de mundo proposta por Freire deverá sempre levar em consideração a experiência de cada sujeito envolvido no processo educativo empreendido. Segundo o próprio verbete:

Da expropriação e do aniquilamento do oprimido brota ampla bagagem de experiências feitas, que lhe tomando o corpo, marcam-lhe a alma. Dos enfrentamentos, sofrenças, a vítima buscou a necessária resistência no sabersobreviver; saber solidário que a protege da completa rendição a que o opressor intenta submetê-la [...] (STRECK, REDIN; ZITKOSKI, 2010, p. 238).

Para Paulo Freire (STRECK; REDIN; ZITKOSKI, 2010, p. 238), dessa forma, o educador não poderá se omitir de, também ele, comunicar sua 
leitura do mundo; tornando claro que não existe uma única lógica de leitura possível. Há tantos mundos quanto leituras dele possíveis (polissemia) e que, portanto, nenhuma leitura é definitiva, terminal. É a educação dialógica proposta por Freire no e com o mundo e com os sujeitos do mundo.

Assim, mais uma vez o poeta nos ajuda a pensar: "Procuro sempre, e minha procura ficará sendo minha palavra” (ANDRADE, 1994, p. 109).

Dessa forma vai se construindo de verbete a verbete - potência a potência de cada palavra/conceito/expressão de Paulo Freire - a possibilidade de uma leitura mais completa e mais reflexiva sobre a vasta obra desse grande pensador brasileiro e sobre a educação. É claro que a leitura do Dicionário não exclui de forma alguma a leitura das obras em sua íntegra - sempre que possível. Mas o Dicionário é também um convite à leitura e suporte a tantos conceitos utilizados e formulados pelo próprio pensador. Assim como Drummond, nos instiga a procurar sempre.

Alguns conceitos menos conhecidos foram também privilegiados na obra, o que colabora para uma maior compreensão do pensamento de Paulo Freire e também uma maior instrumentalização para o leitor de suas ideias. Não podemos deixar de indicar que cada obra de Freire é datada, assim, não podemos também ser leitores ingênuos de seus livros e de suas palavras. Paulo Freire é um "homem de seu tempo" - embora à frente dele, muitas vezes -, dessa maneira, a historicidade de seu pensamento deve ser levada em consideração no momento da apropriação de seus conceitos/ palavras e ideias. Assim, destacamos no Dicionário a construção dos verbetes sempre aliada às obras e aos contextos vividos por Paulo Freire, o que vem colaborar com as observações indicadas.

O Dicionário cumpre exemplarmente sua função, aguçando nosso olhar para a obra freireana e ampliando nossas possibilidades de reflexão sobre nossas próprias práticas, já que se inscreve/insere no que fazer do ato pedagógico de muitos educadores e educandos. E como nos dizeres de Paulo Freire (1996, p. 25), em Pedagogia da autonomia, "não há docência sem discência”, dessa feita o Dicionário Paulo Freire proporciona mais um momento de estudo (discência) para refletirmos sobre a obra e a vida desse importante educador e sobre nossas ações e práticas educacionais (docência). É claro que cada verbete tem a marca de seu autor, por isso se faz também necessário nosso olhar crítico sobre o verbete e a obra a que ele se refere. 
A guisa de conclusão, podemos afirmar que o Dicionário Paulo Freire representa uma grande contribuição para a leitura das obras do próprio autor, mas certamente também contribui de forma efetiva para o campo da educação, sobretudo de uma educação dialógica, do ser no mundo com os educandos e não apenas para os educandos, e nos exorta às leituras de mundo, à construção de uma cidadania plena em nosso século XXI, para que nossa palavra não seja mero discurso, mas "a senha da vida e senha do mundo" (ANDRADE, 1994, p. 109), como diz o poeta.

\section{REFERÊNCIAS}

ANDRADE, C. D. A palavra mágica. In: ANDRADE, C. D. Discurso de primavera e algumas sombras. São Paulo: Círculo do Livro, 1994. p. 109.

BARRETO, V. Paulo Freire para educadores. São Paulo: Arte \& Ciência, 2004.

FREIRE, P. Pedagogia da autonomia: saberes necessários à prática educativa. São Paulo: Paz e Terra, 1996. (Coleção Leitura).

FREIRE, P. Pedagogia do Oprimido. Rio de Janeiro: Paz e Terra, 2005.

Recebido: 02/08/2012

Aprovado: 23/05/2013

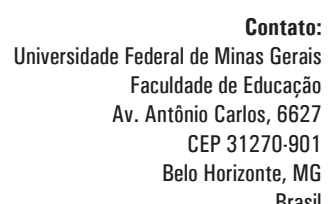

Brasil 